\title{
Ocular Pathology
}

\author{
Hardeep Singh Mudhar
}

The partnership between an ophthalmologist and an ophthalmic pathologist is critical to ensure that the final histopathology report is accurate and intelligible and contains as much relevant information to ensure safe patient management. At all stages of this process, clear verbal and written communication is key; every link in the chain must be robust to ensure the patient comes to no harm. To quote Professor Christopher Fletcher, Director of Surgical Pathology at Harvard Medical School, 'the reality is that the histology report is the principal determinant of diagnosis, likely clinical course and therapy in any patient found to have a mass....' [1].

Ocular pathology specimens travel through three phases: pre-analytical (pre-surgery communication, surgery, request form, specimen handling prior to fixation, fixation and transportation), analytical (processing of specimen, stains, ancillary investigations and histological interpretation by pathologist) and postanalytical (histopathology report, post-report discussion at multidisciplinary meeting, supplementary reporting).

This chapter will cover the following topics:

H. S. Mudhar $(\square)$

National Specialist Ophthalmic Pathology Service (NSOPS), Department of Histopathology,

Royal Hallamshire Hospital, Sheffield, UK

e-mail: hardeep.mudhar@sth.nhs.uk
- Pre-analytical phase

- Pre-surgical planning.

- The ophthalmic pathology request form.

- Handling specimens in theatre before fixing.

- Fixation.

- Transportation of specimens to the histopathology laboratory.

- Post-analytical phase

- Basic histopathology terminology and understanding the histopathology report.

- The use of ancillary investigations in ophthalmic pathology.

- Ocular tumour prognostic factors.

As this chapter is meant to be a practical guide for clinicians, it will not cover the analytical aspects of how the specimen is grossed/cut up, its processing or staining in the ocular pathology laboratory. Many texts are available that cover these steps in detail and interested readers should consult these.

\section{Pre-analytical Phase}

\section{Discussion of Cases Prior to Surgery}

Some cases (complex margins), specimens requiring frozen sections or those requiring special requirements (e.g. certain fixatives), are best discussed in advance with the ocular pathology laboratory. This will ensure the pathology 
laboratory can meet the needs of the surgical procedure and ensure adequate handling without compromising the specimen.

\section{How to Complete the Ophthalmic Pathology Request Form [2]}

A pathology request form is a referral letter and a primary source of communication between the ophthalmologist and pathologist. It is also a medico-legal document. For all specimens submitted to the laboratory, a fully completed request form should accompany each case. Request forms are designed to provide:

- Unique identification of the patient.

- A destination for the report and any charging information.

- The laboratory with the clinician contact details if discussion of the case is required.

- Date and time of specimen collection/removal and investigations required (e.g. histology/ cytology).

- Type of specimen and anatomical site of origin. This is especially important for multiple map biopsies taken from the conjunctiva to establish the extent of ocular surface squamous, sebaceous and melanocytic malignancies. It is critical that the request form include a diagram indicating the precise origin of each biopsy.

- Clinical information so that the pathologist may handle the specimen appropriately and interpret microscopic findings in the proper context.

- An awareness of any health and safety issues with a given specimen.

- Complete information must be supplied on the request form. Each specimen container, no matter how small, should also be labelled with the appropriate patient identification data (minimum of three identifiers, e.g. first and last name, date of birth/age and gender and preferably patient's hospital no).

- The information must be consistent with the request form, to prevent errors in specimen and patient identification.

See Fig. 15.1a-e showing examples of wellfilled out and suboptimally filled out pathology request forms.

\section{Specimen Handling in Operation Theatre Prior to Fixation}

\section{Multiple Specimens from a Surgical Procedure}

As a general principle, specimens from different locations should be placed in separate fixation pots. If multiple pieces of tissue from different sites are placed in the same fixation pot and one of the pieces of tissue turns out to be malignant, it is impossible to ascertain where the tissue has been sampled from.

\section{Orientation of Specimens}

Orientation of specimens is required, to ensure the pathologist can report the margins of excision accurately. This is best done by placing sutures at particular margins and then specifying the sutured margin on the pathology request form in writing or as a diagram (Fig. 15.2a).

\section{Conjunctival Mapping Biopsies}

Conjunctival biopsies comprise thin strips of epithelium and stroma and are prone to curling if placed straight into fixative. They should be attached to sponge or card before placing into the fixative, so that they arrive in the ocular pathology laboratory in a flattened state. The latter facilitates orientation during embedding 


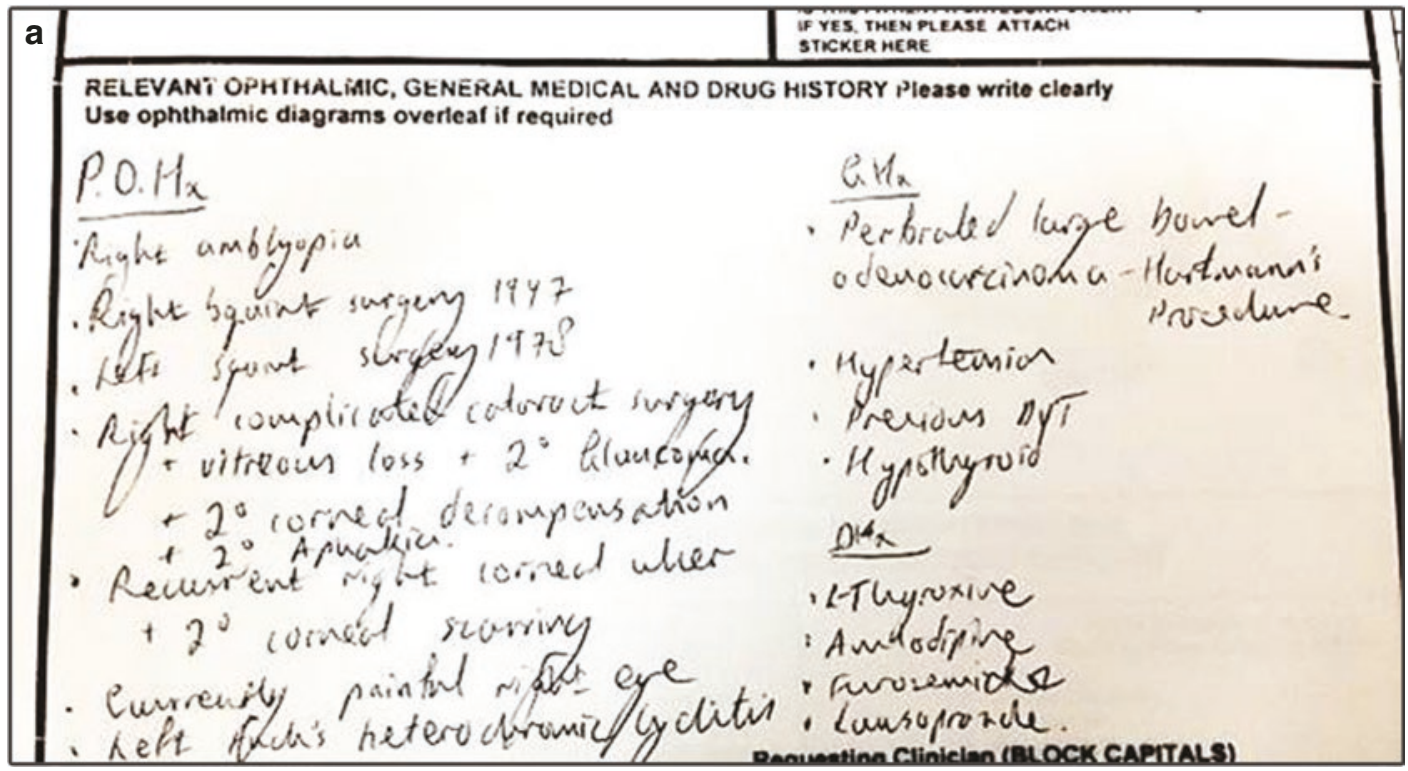

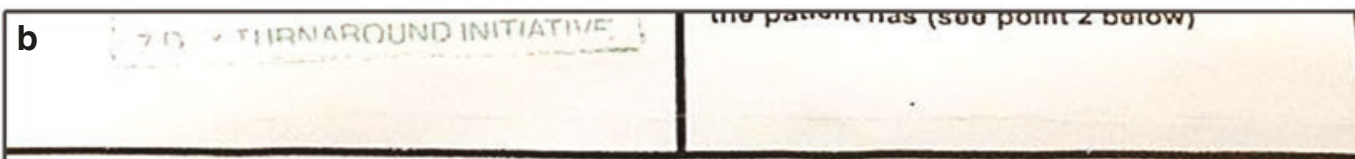

ANT OPHTHALMIC, GENERAL MEDICAL AND DRUG HISTORY Please write clearly thalmic diagrams overleaf if required

$$
\begin{aligned}
& \text { Ho Forwand Protrusian of } R / R \text {. } \\
& \text { on Iyean. } \\
& \text { Un (R) Axial proptosis } \\
& \text { E scan shows circumscribed } \\
& \text { orbital mass at abital apex. } \\
& \text { Orbital lestan is excided or sens } \\
& \text { in histopathology }
\end{aligned}
$$

Fig. $15.1(\mathbf{a}-\mathbf{c})$ These are examples of well-filled out pathology request forms that detail all the relevant information. (c) The surgeon has drawn a very useful diagram, to indicate the orientation of the specimen. $(\mathbf{d}, \mathbf{e})$
Suboptimally filled out pathology request forms that merely state the procedure carried out with no indication of the disease process, no differential diagnosis and no further history 

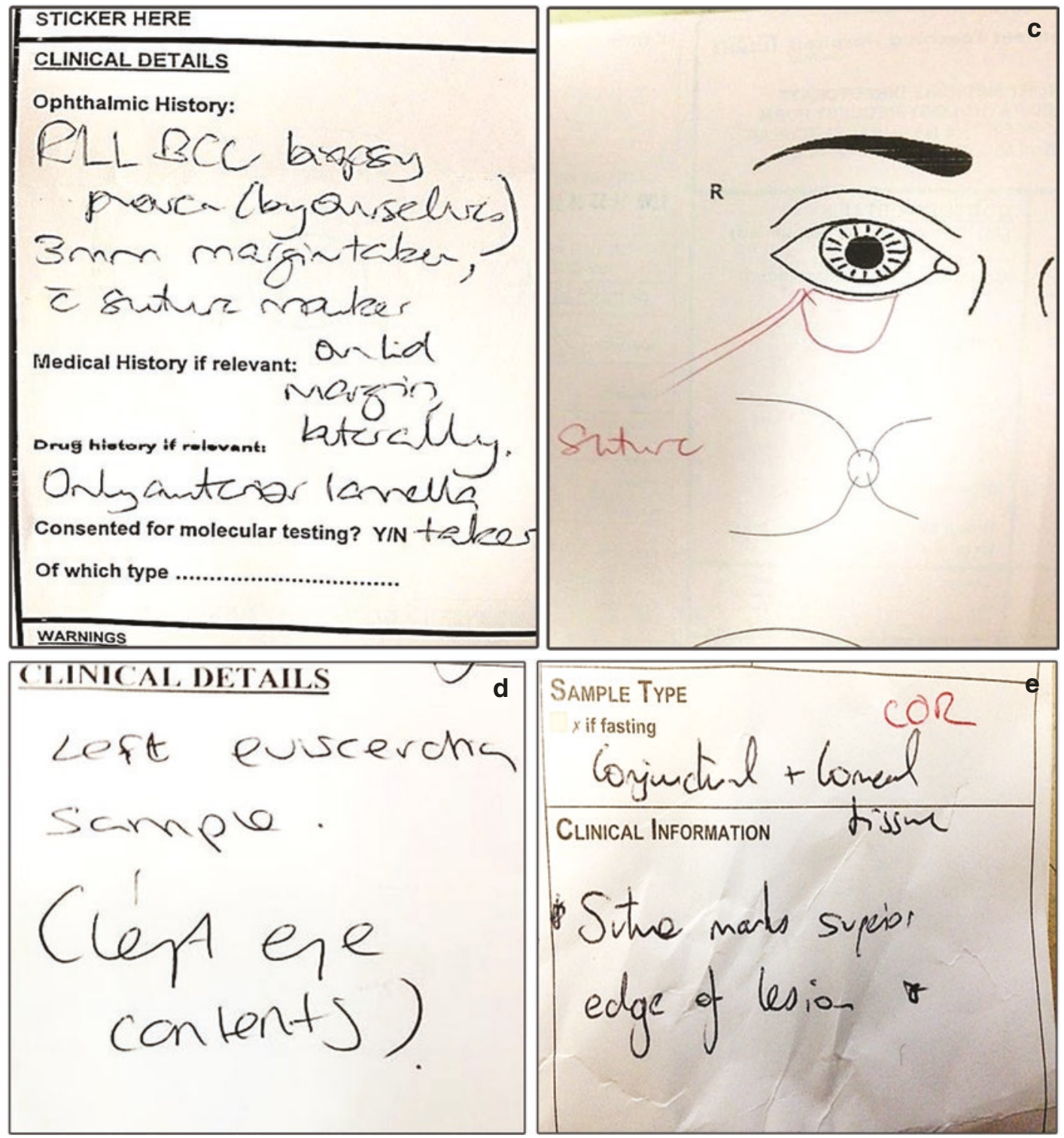

Fig. 15.1 (continued)

and greatly facilitates the histological assessment for the presence or absence of invasion by tumour. If multiple mapping biopsies are performed, the pathology request form must state the precise location of the biopsies. Figure 15.2b shows a very helpful diagram drawn by the surgeon that shows the extent of this patient's conjunctival lesion (shaded areas) and the precise location of the mapping biopsies.

\section{Sampling Fresh Tissue Prior to Fixation}

Some tumours require to be sampled fresh for special genetic/ molecular investigations (diagnostic and prognostic testing) or for research.

- In the case of an enucleation, sample the optic nerve first and place in a separate pot of formalin. This is to prevent fresh tumour 

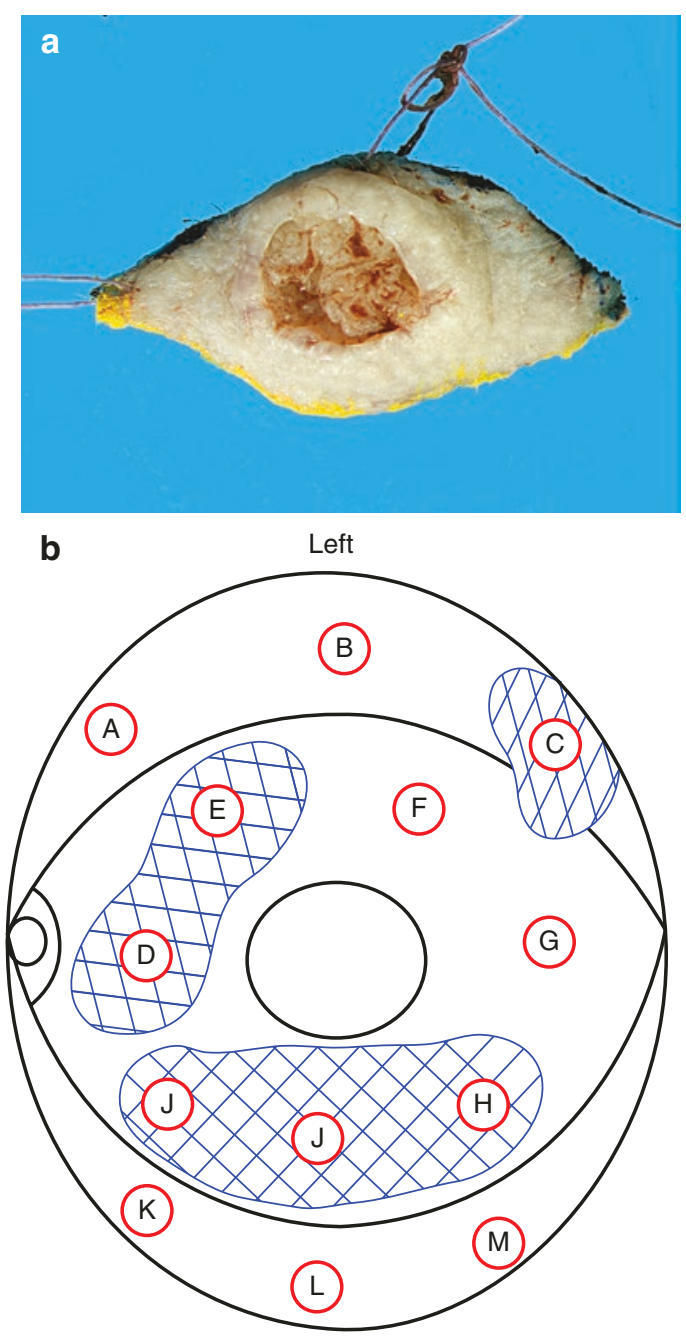

Fig. 15.2 (a) shows an eyelid skin ellipse excision orientated by the surgeon using two sets of sutures. (b) A conjunctival mapping biopsy diagram sketched by the surgeon in theatre. The hash shading denotes the distribution of the lesion and the letters denote the locations of the biopsies that correspond to the formalin pots into which the biopsies have been placed/fixed

contaminating the optic nerve resection margin.

- The globe is transilluminated and using a scalpel, a sclera-choroidal flap is created beneath the tumour, leaving the scleralchoroidal flap hinged along one side. Fresh tumour is harvested with scissors and forceps.

- Fresh tumour is placed in an appropriate medium and vessel.
- Some use a corneal trephine to cut a window into the sclera and choroid.

- After harvesting fresh tumour, the specimen is fixed.

- An alternative strategy is to submit the intact specimen unfixed to the ocular pathology laboratory, where the above steps can be carried out.

\section{Fixation of Ocular Pathology Specimens}

\section{Routine Surgical Specimens}

Standard 10\% phosphate-buffered formalin in a leak-proof container is the fixation of choice (Table 15.1) [3-5]. This will allow routine haematoxylin and eosin staining (H\&E), other special tinctorial stains and immunohistochemistry. In addition, numerous molecular studies for diagnosis and prognosis can be performed on formalin-fixed tissue (Fig. 15.3a).

- If certain molecular biological diagnostic techniques or research is to be done on unfixed tumour samples, the clinician or assistant must remove fresh tumour from the specimen prior to fixing in formalin.

- The formalin should ideally be $10 x$ the volume of the specimen to allow timely penetration of the tissues at room temperature. To ensure this, an adequate sized plastic container is required. Most well-stocked pathology labs have a variety of sizes of plastic container to facilitate this. Many containers come prefilled with formalin (Fig. 15.3a).

- Specimens should be placed into the container that has been pre-filled with formalin. If formalin is poured into a dry container that has the specimen in it, there is a chance that the specimen will be ejected by the formalin and will end up on the bench or floor.

- Specimen containers must then be sealed tightly with the lids to avoid spillage of hazardous formalin.

- Smaller containers are then usually placed in a plastic bag which also accommodates a side compartment for the request form. Follow 
Table 15.1 Various surgical specimen types and fixations used

\begin{tabular}{l|l}
\hline Type of specimen & Type of fixative \\
\hline Eyelid tumour incisional biopsy & $10 \%$ buffered formalin \\
\hline Eyelid tumour excision & $10 \%$ buffered formalin \\
\hline Conjunctival tumour biopsy & $10 \%$ buffered formalin \\
\hline Conjunctival tumour excision & $10 \%$ buffered formalin \\
\hline Intraocular solid tissue biopsy (not FNA) & $10 \%$ buffered formalin \\
\hline Localised resection of intraocular tumour & $10 \%$ buffered formalin \\
\hline Tumour enucleation & $\begin{array}{l}10 \% \text { buffered formalin -remember to sample any fresh } \\
\text { tumour prior to fixation if indicated }\end{array}$ \\
\hline Tumour exenteration & $\begin{array}{l}10 \% \text { buffered formalin-remember to sample any fresh } \\
\text { tumour prior to fixation if indicated }\end{array}$ \\
\hline Orbital tumour biopsy & $10 \%$ buffered formalin \\
\hline Orbital tumour excision & $\begin{array}{l}10 \% \text { buffered formalin-remember to sample any fresh } \\
\text { tumour prior to fixation if indicated }\end{array}$ \\
\hline Lacrimal drainage system/sac biopsy or excision & $10 \%$ buffered formalin \\
\hline Aqueous tap for cytology & $\begin{array}{l}\text { Equal volume of CytoLyt or similar methanol-based } \\
\text { fixative }\end{array}$ \\
\hline Aqueous tap for flow cytometry & RPMI \\
\hline $\begin{array}{l}\text { Vitreous tap or pars plana vitrectomy specimen for } \\
\text { cytology }\end{array}$ & Equal volume of CytoLyt or similar methanol-based fixative \\
\hline $\begin{array}{l}\text { Vitreous tap or pars plana vitrectomy specimen for } \\
\text { flow cytometry }\end{array}$ & RPMI \\
\hline FNabretinal uveal tumour and orbital) & CytoLyt or similar methanol-based fixative \\
\hline
\end{tabular}

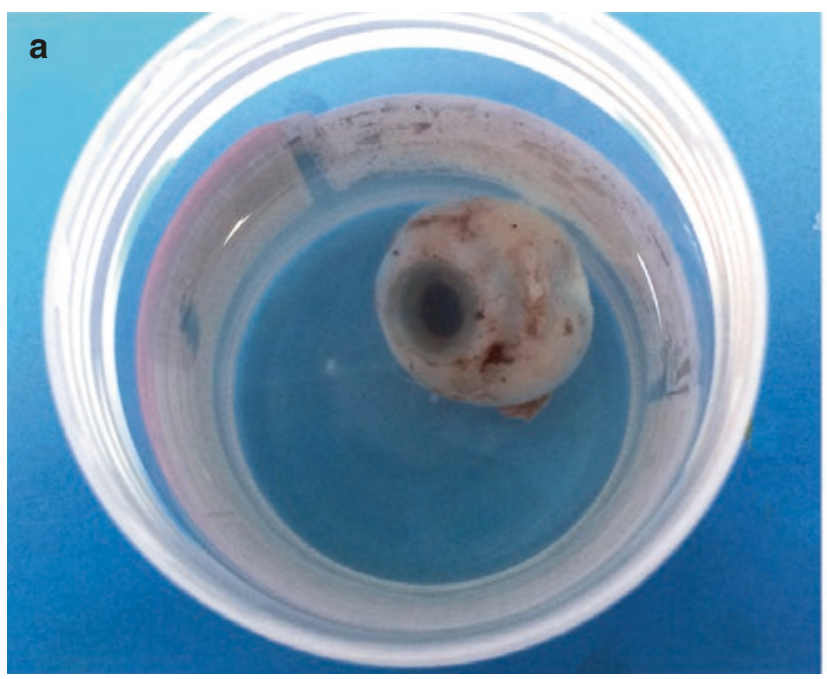

b

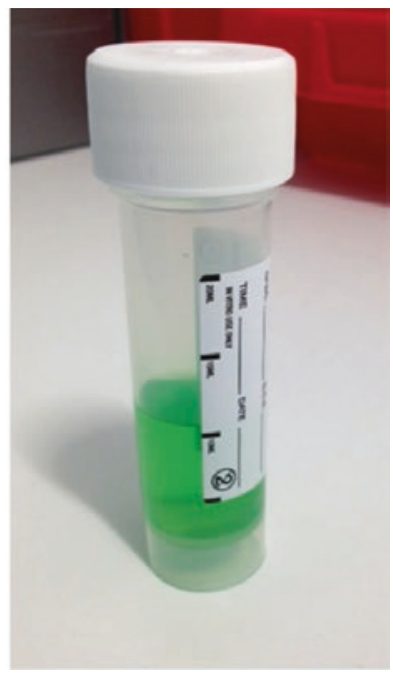

Fig. 15.3 (a) shows a globe specimen (containing a uveal melanoma) in a standard plastic pot, containing $10 \%$ buffered formalin for fixing the specimen. (b) This is a universal tune that contains green, methanol-based cytofixative for intraocular tumour aspiration cytology. The colour of the fluid varies according to the manufacturer. (c) The arrows point to black specs of an aspirated melanotic tumour, fixed in cytofixative in a universal tube. (d)
This is a vitrectomy cassette containing vitreous washings from a patient with suspected intraocular lymphoma, fixed in green cytofixative of a volume equal to the volume of the vitreous washings. (e) This shows an impression cytology plastic ring, fixing in $10 \%$ buffered formalin. (f) A small plastic tube containing buffered glutaraldehyde for the fixation of specimens for transmission electron microscopy 

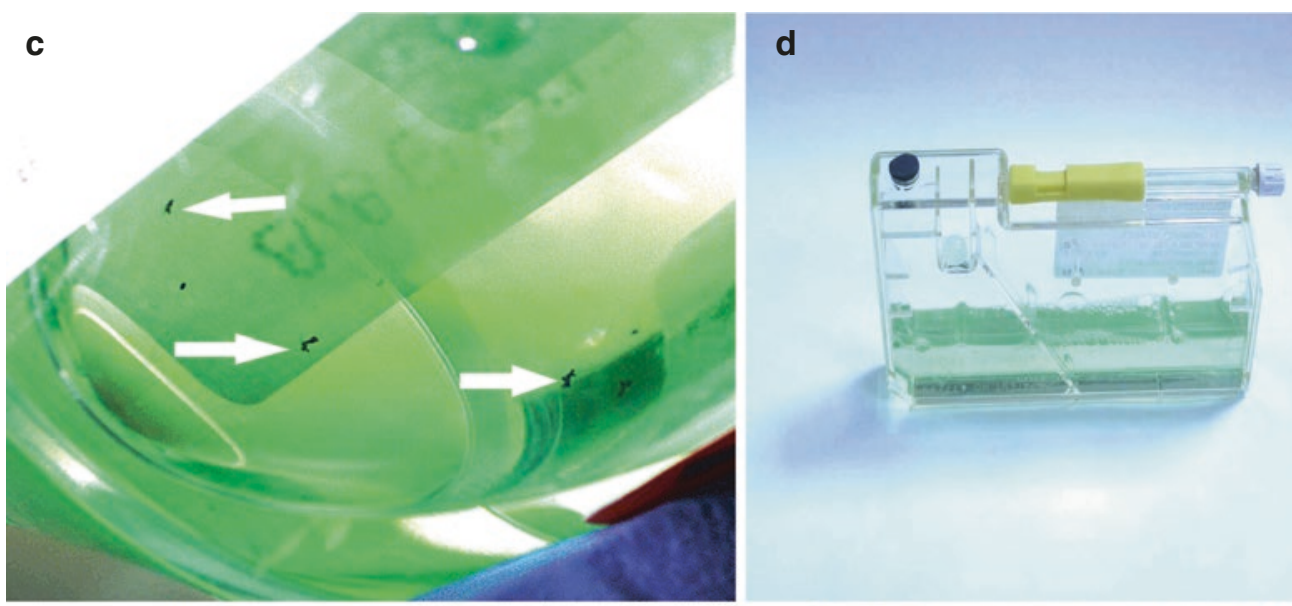

e

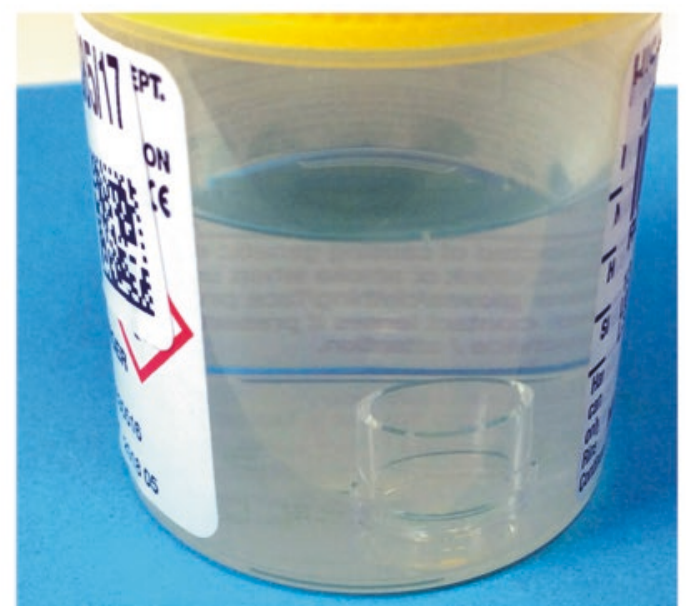

f

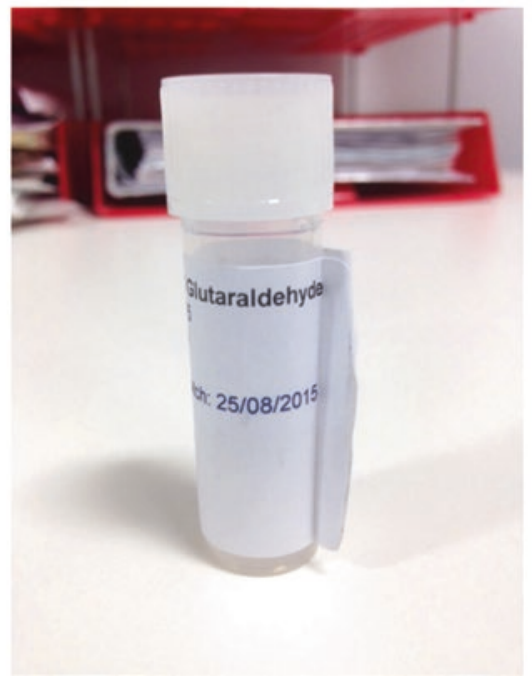

Fig. 15.3 (continued)

your institutional standard operation protocols for additional packaging.

- The appropriate institutional health and safety protocols must be followed when handling formalin.

\section{Which Specimens Should Not Be Fixed?}

- Tissue destined for frozen sections (to assess margins of excision for eyelid, adnexal and orbital tumours).

- Tissue for research or tissue banking.

- Some tumours requiring prognostic information (e.g. sarcomas, paediatric small round blue cells tumours, retinoblastoma) may require special studies on fresh tissue.

- Biopsies destined for flow cytometry (e.g. vitreous and fine-needle aspiration specimens for assessment of lymphoma). In this situation, many practitioners send the cell sample in Roswell Park Medical Institution medium (RPMI) to enhance the survival of the cells.

- Some labs still do Oil Red O staining for suspected cases of sebaceous carcinoma. However, this is being superseded by haematoxylin and eosin-stained (H\&E) sections and immunohistochemistry. 


\section{Fixation of Cytology Specimens}

- Fine-needle aspiration specimens (FNA) are preferably fixed in CytoLyt or Shandon cytofixative (or equivalents) which are methanolbased mild fixatives (Table 15.1). They preserve the cyto-morphology well and permit good-quality DNA to be extracted for molecular diagnostic tests. CytoLyt preserved specimens can be used to make thin-prep slides as well. FNA samples are usually squirted into pre-filled universal tubes that contain the fixative. The syringe used in the collection of the sample may be submitted with the fluid inside. Needles must be removed and the syringe capped. If the specimen is to be fixed, an equal volume of cytology fixative may be drawn up into the same syringe, capped and then agitated gently to mix the sample with the fixative (Fig. 15.3b, c).

- Vitrectomy specimens: It is preferable to receive a pars plana vitrectomy specimen in a vitreous cassette or bag. If samples are required for microbiology, virology, PCR, etc., please remove these from the cassette/ bag before fixation, although, ideally, these should have been sent from the initial core vitreous tap. Vitrectomy samples need to be preserved/fixed in an equal or excess volume of RPMI or cytology fixative. It is important to seal the bag or cassette to prevent leaks in transit (Fig. 15.3d).

- Impression cytology plastic rings can be dropped into a small pot of formalin for fixation (Fig. 15.3e).

\section{Fixation of Specimens Requiring Transmission Electron Microscopy}

- Buffered 2.5-3\% glutaraldehyde is used to fix fresh specimens for transmission electron microscopy. This would be done for cases that are intended for research or in which the original interpretation of an initial tumour biopsy was equivocal and clarification is sought from ultrastructure. It is best to place only part of the fresh tissue into buffered glutaraldehyde, as whilst it is an excellent fixative for ultrastructure, it adversely affects antigen retrieval for immunohistochemistry and extraction of DNA for molecular studies (Fig. 15.3f).

\section{Transporting Specimens to the Pathology Laboratory}

\section{High Risk/Danger of Infection Specimens}

- It is the ophthalmologist's responsibility to indicate on the request form and the specimen pot if the patient is known or suspected to be a 'High Risk/Danger of Infection' category (e.g. HIV, TB, hepatitis B, hepatitis C), to facilitate appropriate handling in the laboratory.

- It is the ophthalmologist's responsibility to ensure that all specimens are submitted to the laboratory in suitable and approved containers.

- Approved specimen containers have leakproof lids and the appropriate hazard warning signs for the fixative, e.g. formalin.

- Specimen containers should be closed securely and placed inside a sealed specimen bag.

- Specimens received leaking or damaged are a danger to all those who come into contact with them, including theatre staff, porters and laboratory staff and can also compromise the diagnosis.

\section{Mailed or Couriered Specimens}

- Specimens mailed or couriered should be packaged in approved containers in accordance with the requirements of the delivery service. To confirm receipt of specimen(s) in the department, it is good practice that a 'confirmation of receipt fax-back' form, providing the senders' confidential fax number, is enclosed with the specimen(s). 


\section{Post-analytical Phase}

\section{Understanding the Ophthalmic Histopathology Report}

The ophthalmic histopathology report contains a lot of specialised pathology terminology that can seem rather bewildering. To understand histopathologic terminology related to tumours, it is best to return to basics. Table 15.2 outlines the tissue of origin and their related tumours that are commonly encountered [6] (Fig. 15.4a-j).

Knowledge of this basic table does go a long way to understanding the various tumours encountered in ocular oncology practice and their behaviour and prognosis. It also allows for a conversation with your local pathologist, who is often equally keen to learn specialised ophthalmology terminology to enhance the quality and clarity of the professional interaction.

\section{Examples of Histopathology Reports with Explanations of Specialised Terminology}

Set out below are examples of ophthalmic histopathology reports that may be encountered in a busy ocular oncology practice with specialised terms defined and figures provided for clarity [6].

\section{Eyelid Tumour Histopathology Report Example}

This full thickness wedge excision contains an invasive neoplasm. It is arising from the Meibomian gland and is composed of pleomorphic cells, with vacuolated cytoplasm, indenting the nuclei. Numerous mitotic figures are present. The individual tumour cells exhibit hyperchromatic chromatin and nucleoli are prominent. Foci of intraepithelial pagetoid spread are seen over the invasive tumour, involving the tarsal conjunctival epithelium and the epidermis of the skin. The invasive tumour shows focal comedo-like necrosis and shows vascular and perineural invasion.

Immunohistochemistry shows that the invasive tumour is positive for adipophilin, EMA and shows nuclear androgen receptor positivity.

The features are those of an invasive sebaceous carcinoma, derived from the meibomian gland. The excision of the invasive component is complete (nearest margin is $3 \mathrm{~mm}$ ). However, the pagetoid spread contaminates the tarsal conjunctival margin and is therefore incompletely excised.

Sebaceous neoplasms can be associated with the Muir-Torre syndrome. Is there a history of internal malignancies in this patient or is there a family history of malignancies?

Table 15.2 Tissues of origin and related tumours

\begin{tabular}{l|l|l|l}
\hline Tissue of origin & Benign & In situ & Invasive malignancy \\
\hline Squamous Epithelium & Squamous cell papilloma & $\begin{array}{l}\text { In situ squamous } \\
\text { carcinoma }\end{array}$ & $\begin{array}{l}\text { Invasive squamous cell } \\
\text { carcinoma }\end{array}$ \\
\hline $\begin{array}{l}\text { Sebaceous gland } \\
\text { epithelium }\end{array}$ & Sebaceous adenoma & $\begin{array}{l}\text { In situ sebaceous } \\
\text { carcinoma }\end{array}$ & Invasive sebaceous carcinoma \\
\hline Melanocytes & Nevus & In situ melanoma & Invasive malignant melanoma \\
\hline Blood cells & $\begin{array}{l}\text { Reactive lymphoid } \\
\text { hyperplasia }\end{array}$ & & Lymphoma or leukaemia \\
\hline Soft tissue & Lipoma & & Liposarcoma \\
\cline { 2 - 4 } & Haemangioma & & Angiosarcoma \\
\cline { 2 - 4 } \\
\hline
\end{tabular}


a

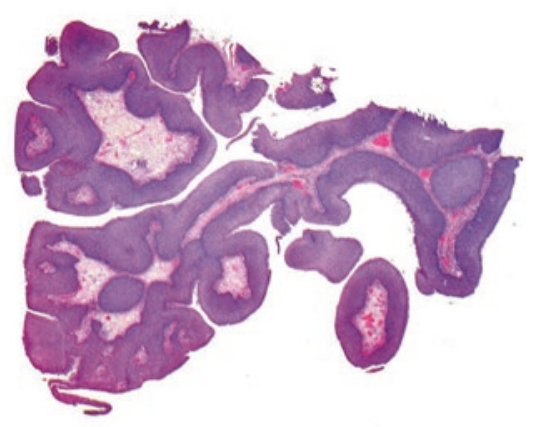

b

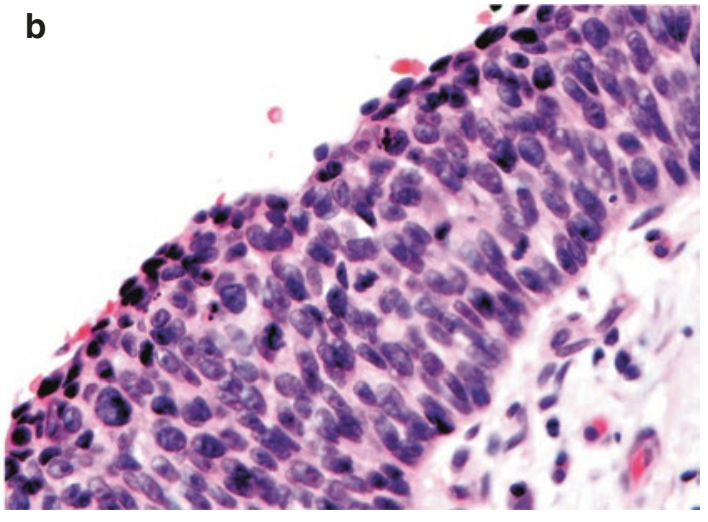

retinoblastoma. The asterisk indicates pink irregular necrotic tumour. (q) H\&E of an adenoid cystic carcinoma of the orbit showing tumour around a nerve (arrow). This is perineural invasion. (r) Melanoma cells (stained red) are within the lumen of a lymphatic channel (stained brown). This is intra-lymphatic spread of tumour. (s) H\&E of conjunctival squamous dysplasia (mid- to right aspect of image). The latter epithelium is thicker compared to the epithelium on the left which is much thinner. (t) $\mathrm{H} \& \mathrm{E}$ of a spindle-rich uveal melanoma. (u) H\&E of an epithelioid rich uveal melanoma. The cells are much rounder and larger compared to the spindle cells in plate T. This is because they possess larger nuclei and more cytoplasm. (v) This is a Periodic Acid Schiff's (PAS) stain of a uveal melanoma showing rounded clones of tumour cells surrounded by pink/purple basement membrane boundaries, so-called loops. (w) This is a fluorescence in situ hybridisation (FISH) image showing different chromogenic-labelled DNA probes (green, red, blue, yellow) hybridising with various gene loci. (x) This is an orbital lymphoma stained with a B-cell marker antibody called CD20, by the technique of immunohistochemistry. The positive cells stain brown (different coloured chromogens can be employed such as red, brown, blue, etc.). Note how it is the cell membranes that stain, imparting a chicken-wire appearance. (y) This is an orbital lymphoma stained with Ki67 antibody by immunohistochemistry. The antibody stains the nuclei brown. The proliferation fraction of the tumour can be estimated by counting the number of stained nuclei out of 100 cells. (za) This trace shows a typical polyclonal population of B-cells when assessed for B-cell IgH rearrangement by PCR. Note the spread of varying sized peaks in a Gaussian dumbbell curve configuration. The histology showed a reactive lymphocytic population in the vitreous with a final diagnosis of chronic vitritis. (zb) This trace shows a typical monoclonal population of B-cells when assessed for B-cell $\mathrm{IgH}$ rearrangement by PCR. The final diagnosis was vitreo-retinal high-grade B-cell lymphoma 

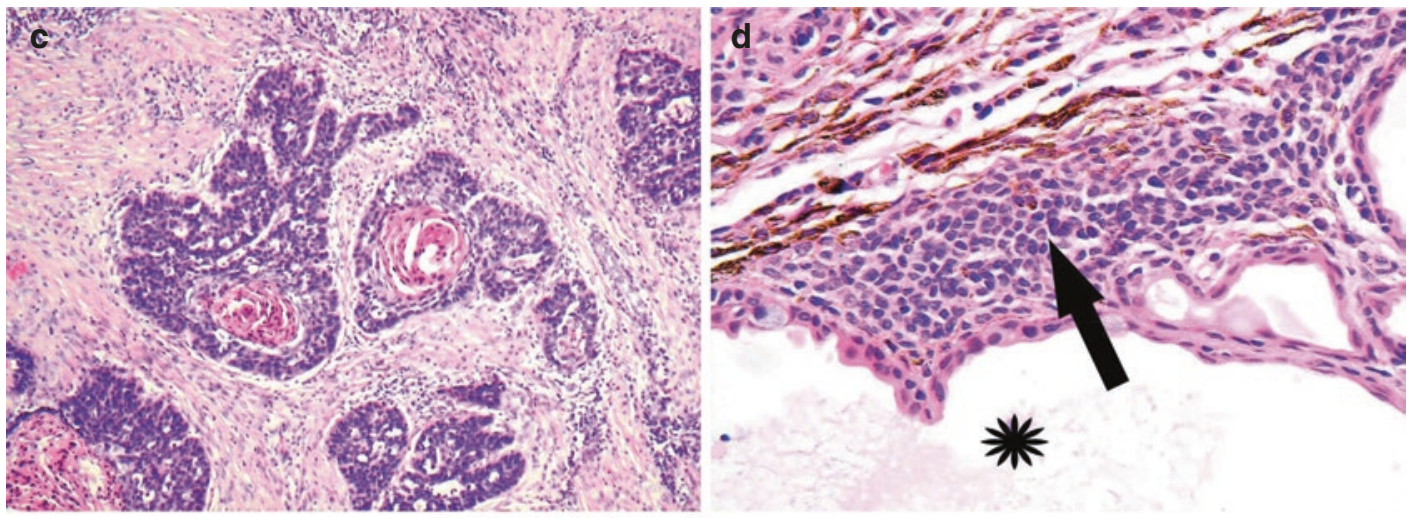

$$
\text { e }
$$

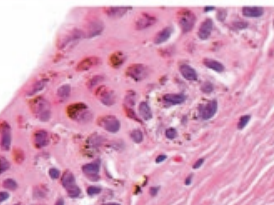

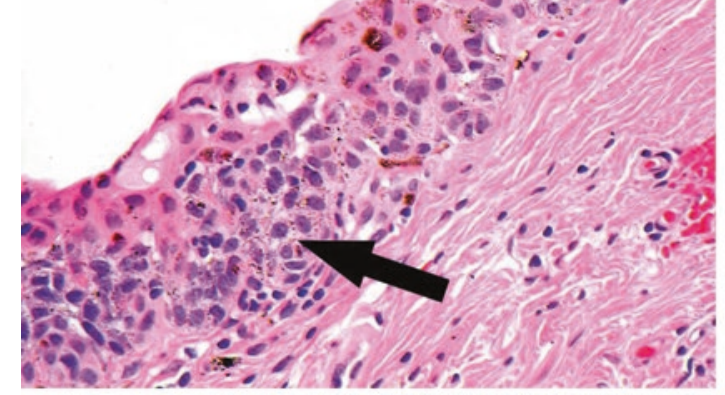
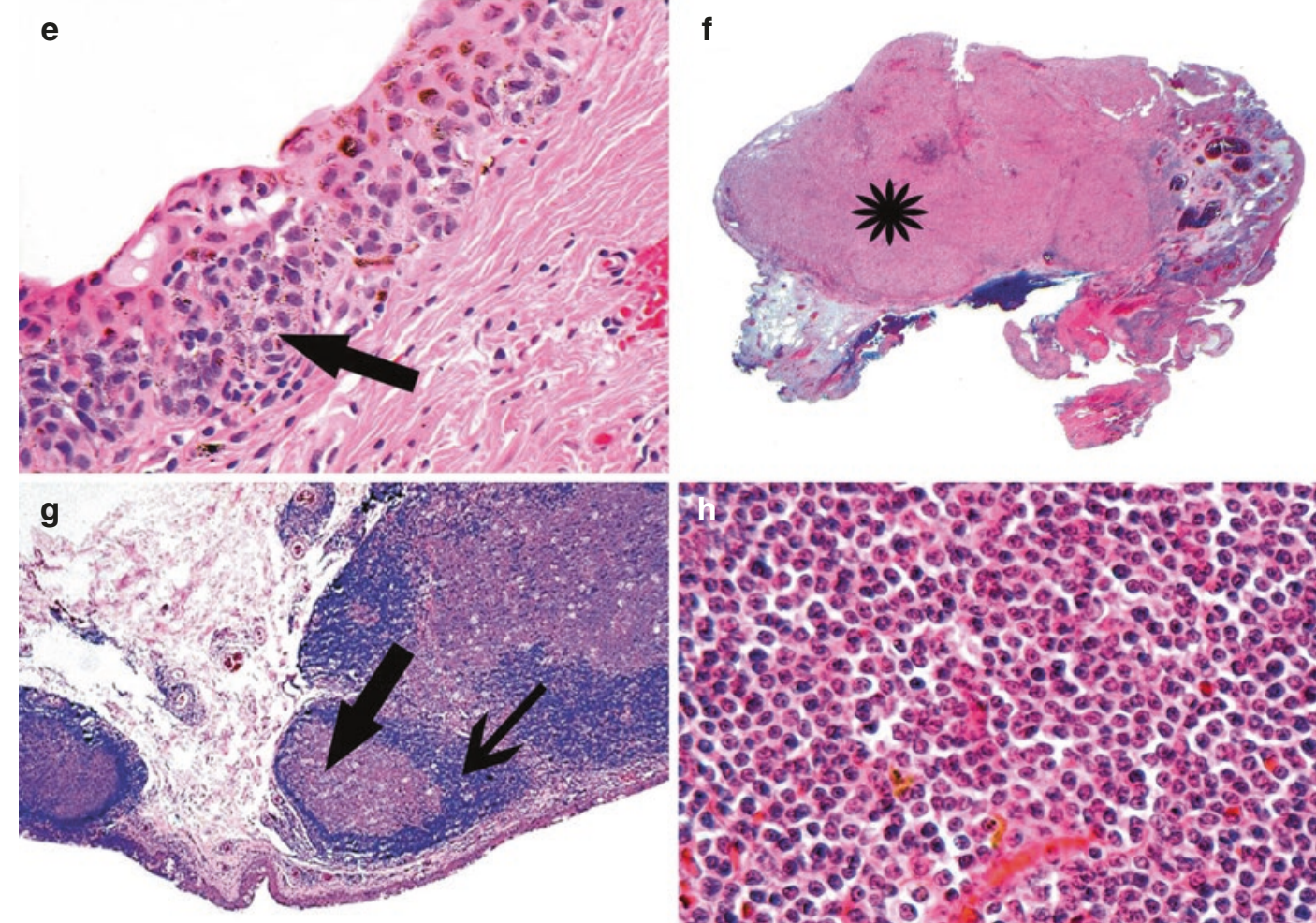

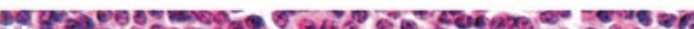

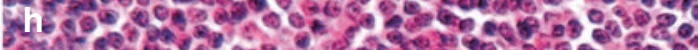

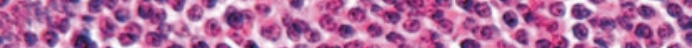

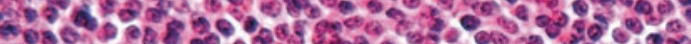

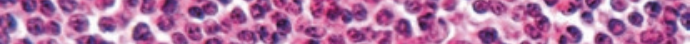

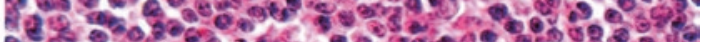

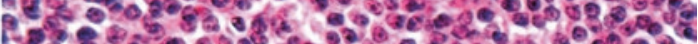

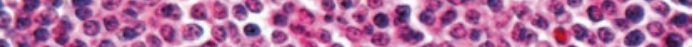

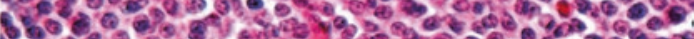

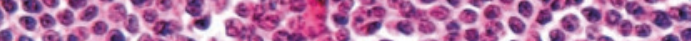

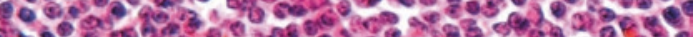

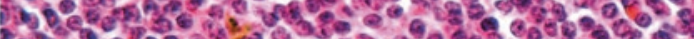

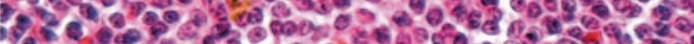
(4) Lem 10 lo $\angle 9$ (1) S.

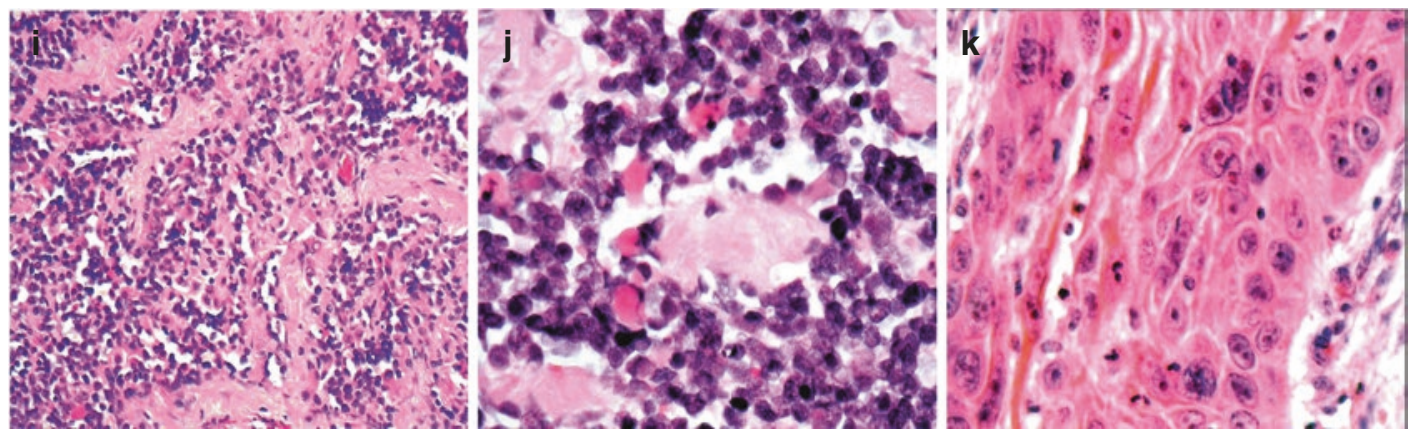

Fig. 15.4 (continued) 

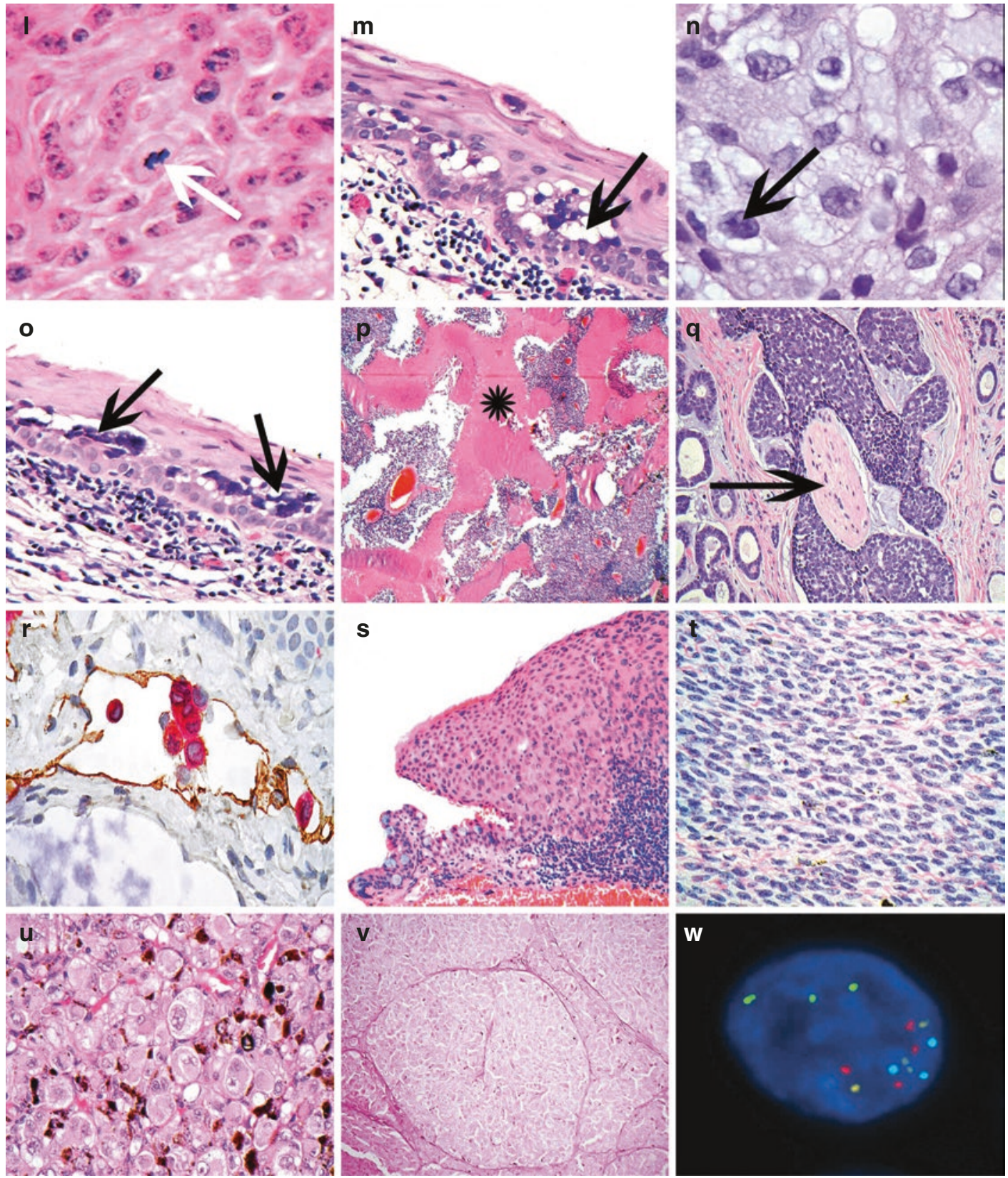

w

Fig. 15.4 (continued) 

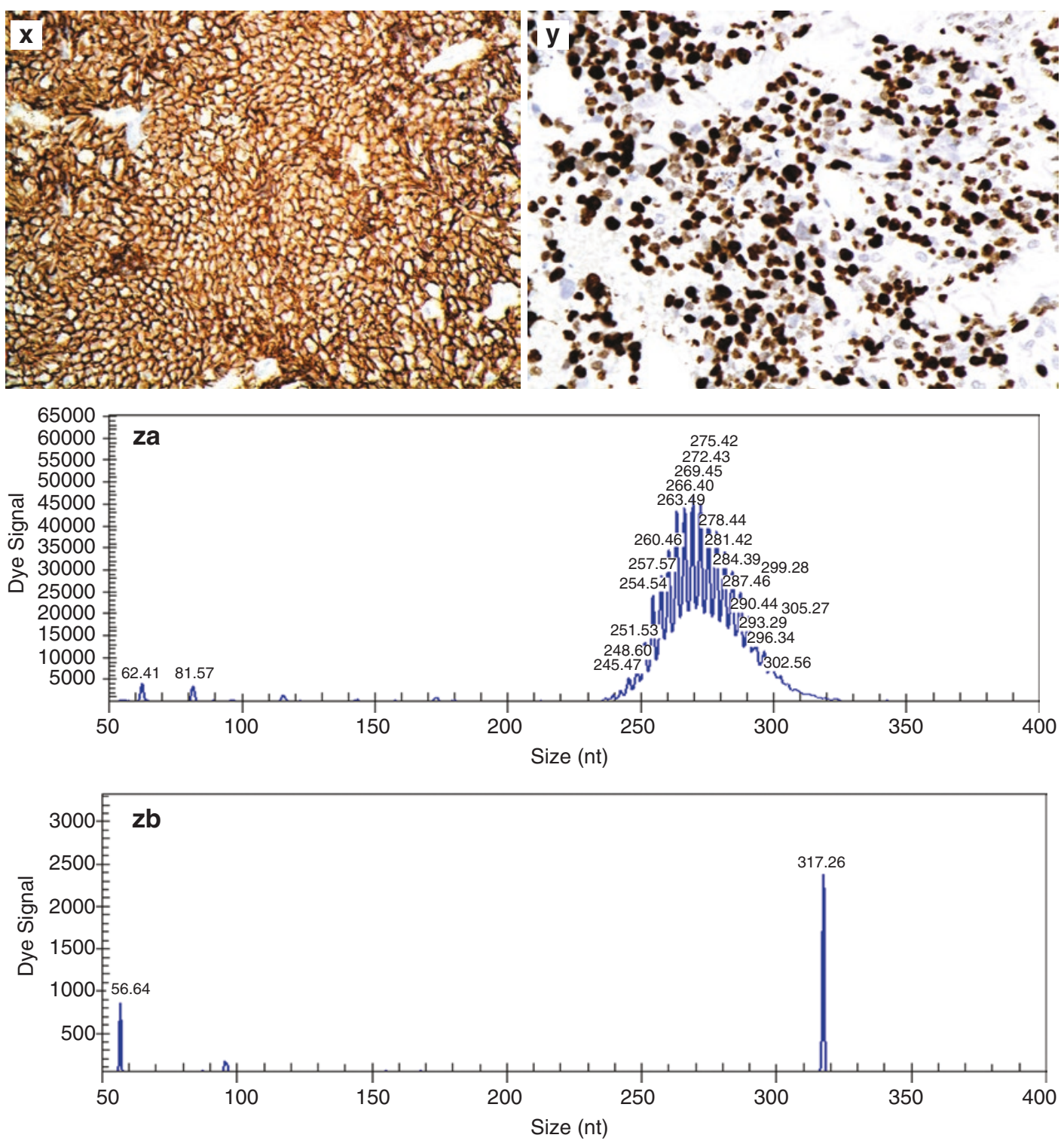

Fig. 15.4 (continued)

\section{Terminology Explained}

Invasive Malignant tumours invade through basement membranes into the surrounding tissue and can metastasise by invading into blood vessels and lymphatics.

Neoplasm Literally means 'new growth' (derived from Greek).
Pleomorphic Variation is size and shape of the nucleus and cytoplasm of the individual tumour cells. This is a feature of malignant cells that have lost their normal constraining signals (Fig. 15.4k).

Mitotic Figures Prophase, metaphase, anaphase, telophase and cytokinesis are the five phases of mitosis (refer to any intermediate biology textbook). 
Mitotic figures are seen in normal and repairing tissues. An example of a normal tissue containing mitotic figures is the proliferative phase of endometrial glands and stroma. When injured tissue is regenerating, it is common to see many mitotic figures, e.g. regenerating epithelium in skin after trauma. Benign and malignant tumours contain mitotic figures. Malignant tumours tend to have more mitotic figures than benign tumours. Of the malignant tumours, poorly differentiated tumours tend to have higher mitotic figure counts compared to better differentiated tumours. In malignant tumours, the mitotic figures can have an abnormal morphology that is not seen in benign, normal or regenerating tissues. These include tripolar or multipolar forms (Fig. 15.41).

Vacuolated A bubbly appearance to the cytoplasm due to the presence of various substances. In this case, it is lipid as the diagnosis is sebaceous carcinoma. It could be mucin (mucin forming carcinomas) or glycogen (e.g. renal cell carcinoma). The products made by tumour cells can be very helpful for classification (Fig. 15.4m).

Hyperchromatic Chromatin Simply means dark staining DNA in the nucleus. This is a feature of malignant cells (Fig. 15.4n)

Intraepithelial Within the confines of the epithelium.

Pagetoid Horizontal and vertical spread of malignant tumour cells as individuals or groups within epithelium. Named after Sir James Paget, an English surgeon and pathologist who described Paget's disease that shows this pattern of spread. Tumours that show this pattern of spread include malignant melanoma and sebaceous carcinoma (Fig. 15.4o).

Comedo Literally means like a 'zit'. Malignant tumour cells forming sheets are hypoxic in the middle and undergo necrosis. The appearance is that of a necrotic centre surrounded by a viable rim of malignant tumour cells. If the tissue is squeezed gently during handling, the necrotic tumour centre oozes out of the cut surface like zits being squeezed.

Necrosis Cell death with loss of cell contents to the exterior. Malignant tumours that outstrip their blood supply often become necrotic (Fig. 15.4p).

Vascular and Perineural Invasion Malignant tumours can invade into vessels and metastasise to distant locations. They also follow the paths of least resistance and spread along natural tissue scaffolds such as nerves (Fig. 15.4q, r).

Immunohistochemistry A common ancillary technique employed in histopathology to detect signature proteins using antibodies in various disease processes. In malignant tumours, it can help to type the tumour (e.g. carcinoma, lymphoma, melanoma, sarcoma) and can also reveal vital prognostic and therapeutic information.

Carcinoma A malignant epithelial neoplasm.

\section{Further Comments}

The last comment in the report relates to the surgical margins. In this case, the contamination of the conjunctival margin may necessitate mapping biopsies to ascertain the extent of the pagetoid spread that would inform subsequent therapy choices.

\section{Conjunctival Tumour Histopathology Report Example}

The bulbar conjunctiva contains a focus of in situ squamous carcinoma, arising in a background of various degrees of dysplasia. No invasion is identified in the planes examined. The surgical margins are clear. The background stromal tissue shows solar elastosis.

\section{Terminology Explained}

Dysplasia Derived from Greek meaning 'disordered growth'. Dysplasia is a term that is applied to epithelium. Histologically, the individual epithelial cells show pleomorphism (defined above), can have hyperchromatic nuclei and have a disor- 
ganised distribution within the epithelium. Mitotic figures may be seen. Pathologists can grade epithelial dysplasia according to how much of the epithelial thickness is occupied by the dysplastic cells. For example, common classifications of epithelial dysplasia are mild, moderate and severe or low-grade and high-grade. When the full thickness of the epithelium is consumed by dysplastic cells and the basement membrane has not been breached, it is called carcinoma in situ and is said to be pre-invasive. Invasion is not present. Therapeutic intervention at this stage of the disease is potentially curative (Fig. 15.4s).

\section{Intraocular Tumour Histopathology Report Example}

This enucleation contains a malignant melanoma of uveal type. It is located in the ciliary body and choroid and has a diffuse component. It is composed of spindle and epithelioid cells and has up to 15 mitotic figures per $10 \mathrm{hpf}$. Closed loops and networks matrix patterns are seen. Focal tumour necrosis is present. The tumour does not breach Bruch's membrane. There is no scleral invasion. The vortex veins are tumour-free. FISH analysis on the tumour has shown monosomy 3 and a gain of iso-chromosome $8 \mathrm{q}$ in $90 \%$ of the cells.

Summary: A pathological stage pT3b uveal melanoma of the ciliary body and choroid. The presence of monosomy 3 and iso-chromosome $8 \mathrm{q}$ indicates a poor prognosis.

\section{Terminology Explained}

Spindle and Epithelioid Cells This refers to the shape of the cells found in uveal melanoma, referred to as the Callender classification. This is of prognostic significance; more epithelioid cells carry a worse prognosis [7] (Fig. 15.4t, u).

Per 10hpf This is a mitotic count performed in 10 'high-power fields' (each with an area of $0.152 \mathrm{~mm}^{2}$ and usually corresponding to a $\times 40$ lens on a high-quality light microscope).

\section{Closed Loops and Networks' Matrix}

Patterns This refers to the presence of specific basement membrane patterns stained with a periodic acid-Schiff (PAS) stain, present around expanding nests of melanoma cells. These matrix patterns are related to a poorer prognosis in uveal melanoma [8] (Fig. 15.4v).

FISH: Fluorescence In Situ Hybridisation FISH has been used in this case to gain genetic data on the status of chromosomes 3 and 8 in this uveal melanoma. Uveal melanoma genetics data is a powerful predictor of prognosis [9-13] (Fig. 15.4w).

Pathological Stage pT3b This refers to the TNM pathological classification of the stage of the uveal melanoma [14].

\section{Further Comments}

Ophthalmic pathologists will use the $\mathrm{TNM}^{14}$ or AJCC [15] cancer staging manuals to include all of the relevant tumour prognostic information required for prognosis and treatment planning for uveal melanoma.

Also note how the report has combined histopathological and genetic data. This is increasingly common and is called integrated reporting, in the context of individualised oncology practice.

\section{Orbital Tumour Histopathology Report Example}

This orbital fat biopsy contains numerous reactive lymphoid aggregates. On this background, there is a larger expansile nodule composed of small lymphocytes, with a monocytoid appearance, associated with cells exhibiting lymphoplasmacytic differentiation. These monocytoid cells are positive for B-cell markers using immunohistochemistry (CD20 and CD79a positive) and are negative for CD5, CD10, Cd23 and Cyclin D1. The Ki67 fraction is 5\%. PCR for IgH rearrangement shows clonal peaks in FR1, FR2 and FR3 confirming an unequivocal clonal population of B lymphocytes.

The appearances are those of an indolent B-cell lymphoma, sub-classification: extranodal marginal zone lymphoma of MALT type 
(MALToma-WHO classification). This patient requires referral to your haemato-oncology service for further management.

\section{Terminology Explained}

Reactive Lymphoid Aggregates These are nonlymphomatous collections of lymphocytes comprising a germinal centre of larger lymphocytes undergoing apoptosis surrounded by a mantle of smaller lymphocytes. They indicate chronic antigenic stimulation and contain polyclonal groups of B lymphocytes.

Monocytoid Appearance It is common for a pathologist to describe the appearance of certain tumour cells with peculiar adjectives. Monocytoid means a lymphocyte nucleus within a clear cytoplasm, resembling a fried egg.

B-cell Markers This refers usually to immunohistochemistry markers for staining B-cells. Common markers include CD20 and CD79a. It is vitally important that any lymphoma should be differentiated into B or T cell type for diagnostic, prognostic and treatment purposes (Fig. 15.4x).

The Ki67 Fraction This refers to the \% of cells that express Ki67. This protein is expressed in cells in all non-G0 phases of the cell cycle. It gives an indication of how fast tumour cells are proliferating. A higher Ki67 fraction tends to predict aggressive tumour behaviour (Fig. 15.4y).

PCR for IgH Rearrangement PCR, polymerase chain reaction. IgH-heavy chain of the immunoglobulin molecule. This is a common molecular diagnostic test performed in cases of suspected lymphoma.

Clonal Population of $\boldsymbol{B}$ Lymphocytes This means a population of B-cells all expressing the same heavy chain of immunoglobulin. Monoclonality usually means lymphoma but not always. Reactive lymphoid populations can contain monoclonal lymphocyte populations. The pathologist will always interpret the results of ancillary diagnostic/supportive molecular tests in the context of the clinical and histopathological findings (Fig. 15.4za, zb).

\section{Further Comments}

Lymphoma diagnosis often requires histopathological, immunohistochemical and molecular diagnostic tests to secure a firm diagnosis. An ophthalmic pathologist will often discuss the case with a specialist lymphoma pathologist and the case reviewed at the local multidisciplinary team meeting to plan further investigations (e.g. staging) and treatment. Again, note how the report contains integrated items of histopathological and molecular data and a suggestion for referral to an appropriate clinical team.

\section{Common Ancillary Investigations Used in Ophthalmic Histopathology}

Ancillary investigations are used to assist in making a diagnosis and to give prognostic information. The results of ancillary tests must always be interpreted alongside the light microscopic histological features in order to avoid an over or under diagnosis.

\section{Immunohistochemistry}

This is the application of antibodies to antigens in formalin-fixed, paraffin-embedded sections, visualised with various coloured chromogens. The antibodies are directed toward certain proteins that are expressed by specific cell types. Tumour cells express specific proteins allowing the tumour type to be established, which otherwise may be difficult on light microscopic examination alone.

\section{Diagnostic Application}

Example 1 Figure 15.5a shows a biopsy of the conjunctiva. The morphology shows atypical cells occupying the full thickness of the epithelium. The morphological differential diagnosis includes in situ melanoma, in situ squamous carcinoma and in situ sebaceous carcinoma. These are tumours with varying behaviour, prognosis and treatments so the diagnosis must be refined. Application of a small panel of antibodies allows discrimination. In this case, the tumour is positive for Melan A antibody 

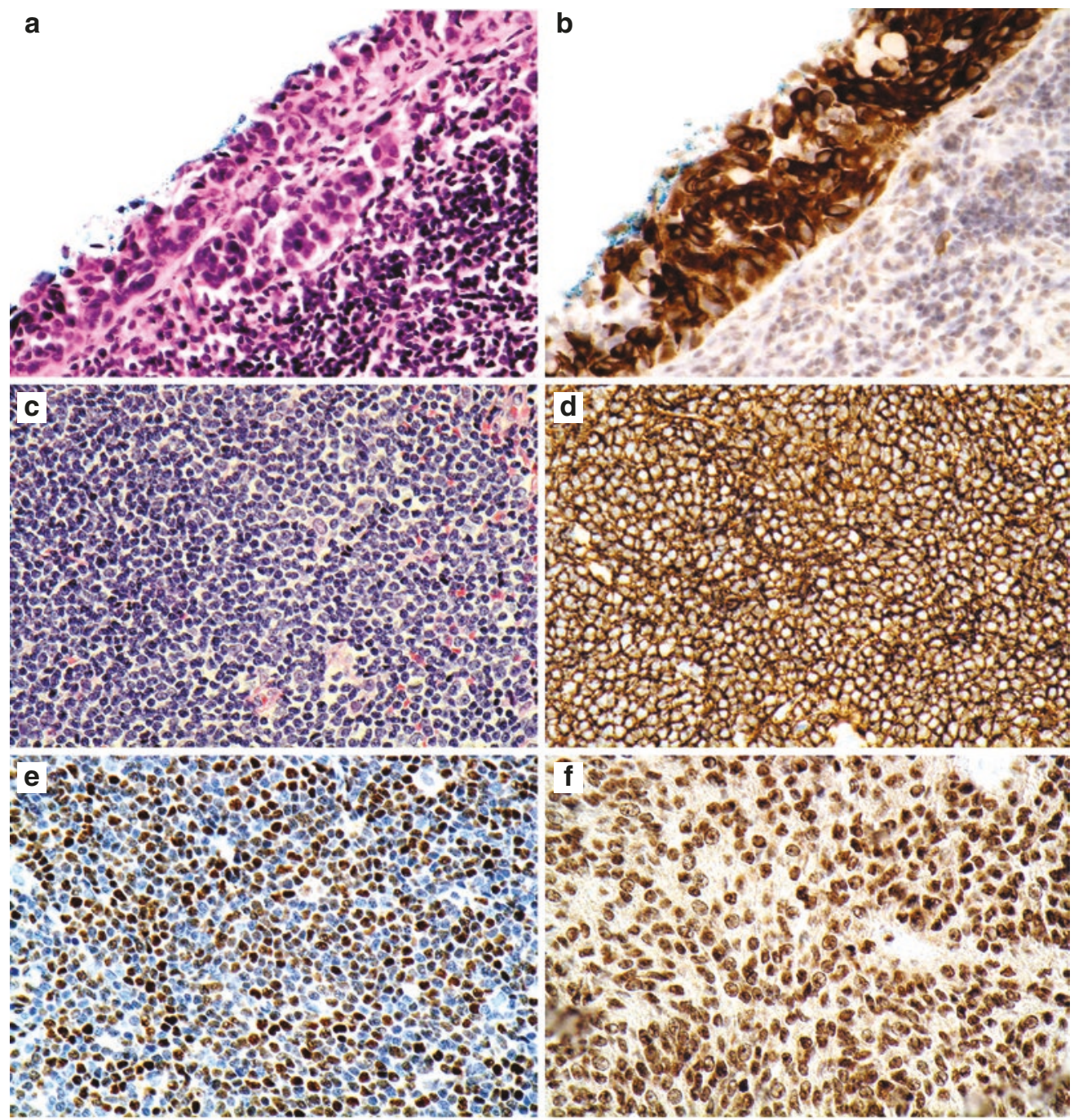

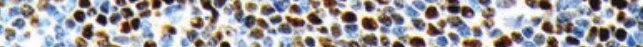
2. 630.20 .

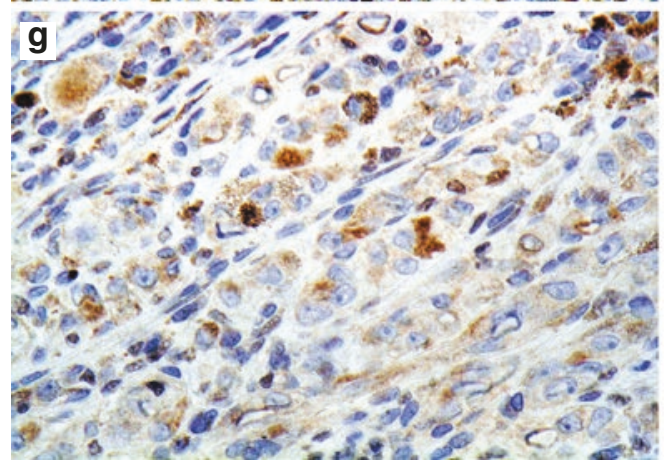

Fig. 15.5 (a) $\mathrm{H} \& \mathrm{E}$ of a conjunctival biopsy showing amelanotic atypical cells occupying the full thickness of the epithelium. (b) Melan A immunohistochemistry shows positivity in the atypical intraepithelial cells (brown signal), indicating in situ melanoma. (c) H\&E showing a diffuse sheet of round lymphoid cells. (d) The lymphoid cells in Fig. (c) are positive for CD20. (e) The lymphoid cells in

panel $\mathbf{c}$ are positive for nuclear Cyclin D1, indicating a diagnosis of Mantle cell lymphoma. (f) BAP 1 immunohistochemistry on a uveal melanoma showing nuclear positivity. (g) BAP 1 immunohistochemistry on another uveal melanoma showing a lack of nuclear staining. (e, courtesy of Dr. Karen Sisley, Senior Lecturer, Department of Oncology, Sheffield University, Sheffield, UK) 
(Fig. 15.5b) and negative for cytokeratin and androgen receptor. Melan A is a protein specific to melanoma cells. Cytokeratins are expressed by epithelial malignancies (in situ squamous and sebaceous carcinoma), and androgen receptor is expressed strongly by in situ sebaceous carcinoma. The final diagnosis is in situ melanoma.

Example 2 This orbital biopsy shows a lymphocytic infiltrate that histologically is a lymphoma (Fig. 15.5c). However, every lymphoma must be precisely sub-typed as each lymphoma has a specific morphology, immunohistochemical phenotype, molecular signature, prognosis and treatment (WHO classification). Application of a panel of lymphoid markers shows that this lymphoma is of B-cell phenotype (positive for CD20, Fig. 15.5d) and furthermore is positive for Cyclin D1 (Fig. 15.5e) which indicates the precise diagnosis of mantle cell lymphoma [16].

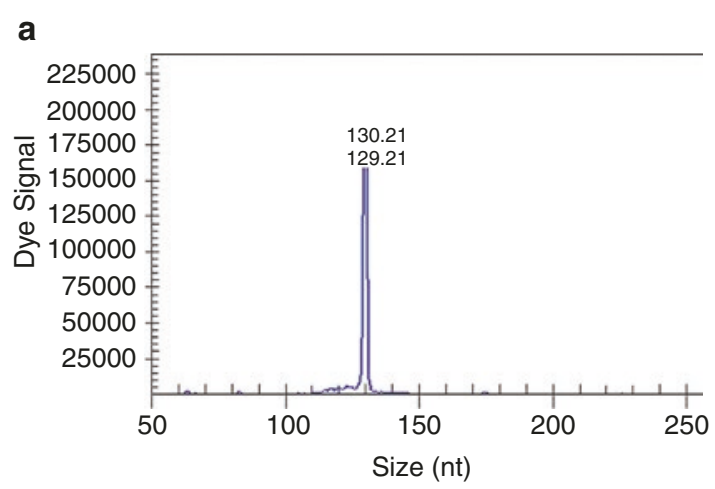

Fig. 15.6 (a) This trace shows a single, sharp peak indicating a monoclonal population of B-cells when assessed for B-cell IgH rearrangement by PCR. (b) MLPA study of uveal melanoma showing 'piano key' score. The arrow points to an area of loss of one copy of chromosome 3 (monosomy 3). (c) FISH study of an orbital alveolar rhabdomyosarcoma showing separate green and red hybridisation dots within the nucleus. This indicates rearrangement of the FOXO1 gene on chromosome 13q14. (d) FISH study showing three uveal melanoma nuclei. The red dot indicates one copy of chromosome 3 (monosomy 3 ), and the extra blue dot in the nucleus on the right indicates a gain of chromosome 8q. (e) Array CGH result from a uveal melanoma. Chromosome deletions in red are on the left of the and gains in blue on the right of the chromo-

\section{Prognostic Application}

Figure $15.5 \mathrm{f}$ shows a uveal melanoma that shows nuclear positivity for BAP1. Figure $15.5 \mathrm{~g}$ shows nuclear BAP-1 absence in another uveal melanoma, an indication that the tumour is of probable monosomy 3 genotype, associated with a poor prognosis [17].

\section{Polymerase Chain Reaction (PCR)}

\section{Diagnostic Application}

Sometimes, it is difficult to ascertain on light microscopy whether a lymphoid infiltrate is reactive or neoplastic. Formalin-fixed, paraffinembedded extracted DNA can be tested for lymphocyte clonality, to establish whether a population of lymphoid cells are polyclonal (reactive-not lymphoma) or monoclonal (likely lymphoma) (Fig. 15.6a).

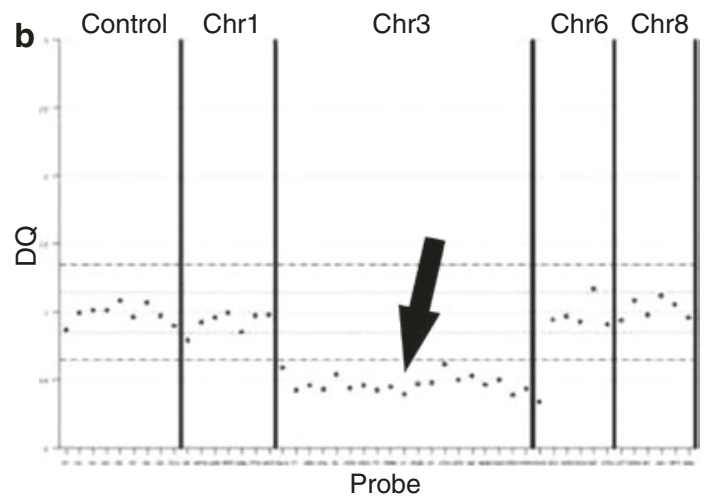

somes. This study shows a loss of chromosome 3 (left arrow) and a loss of $8 p$ and gain of $8 q$ (right arrow). Other changes include deletion of chromosome 1 and gains of chromosome 20 and 21. (f) SNP array data from a uveal melanoma showing loss of one copy of chromosome 3 (left arrow) and loss of $8 \mathrm{p}$ and gain of $8 \mathrm{q}$ (right arrow). (Courtesy of: b, Professor Sarah E Coupland-Professor of Ophthalmic Pathology, Liverpool University, Liverpool UK; c, Dr Duncan Baker, Cytogeneticist, Sheffield Children's Hospital, Sheffield UK; d, Dr Karen Sisley, Senior Lecturer, Department of Oncology, Sheffield University, Sheffield UK; f, Dr Natasha van Poppelen and Dr Rob Verdijk, Department of Pathology, Erasmus Medical Centre, Rotterdam, Netherlands) 

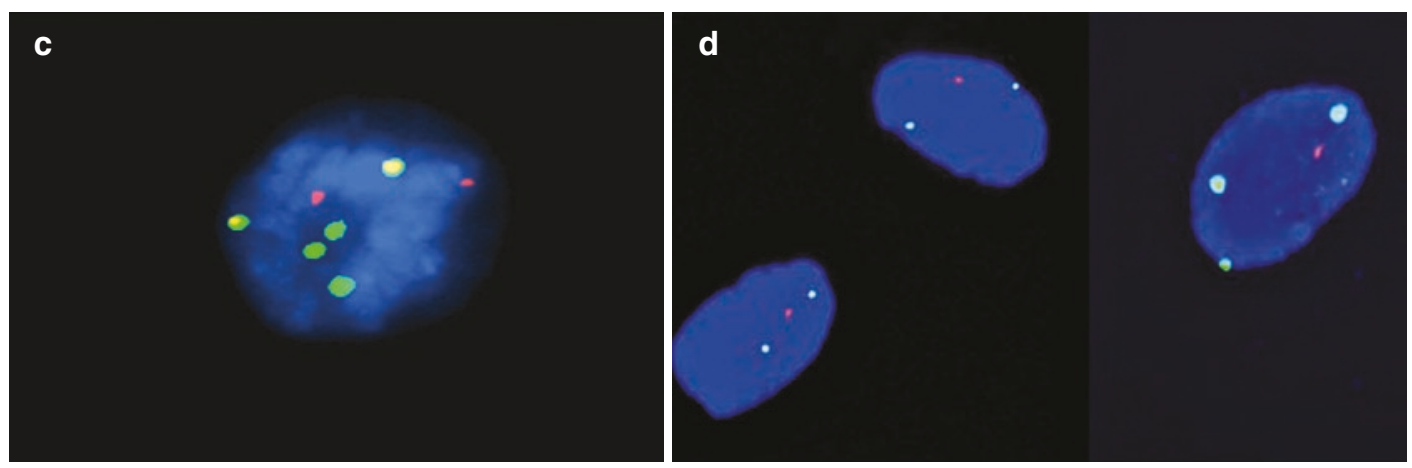

e

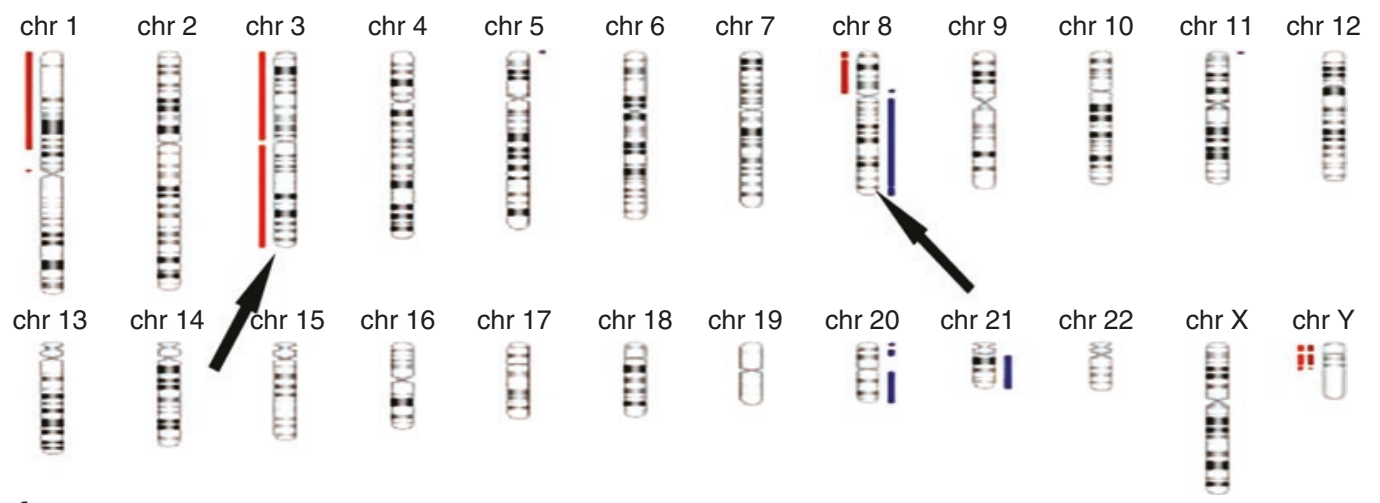

f
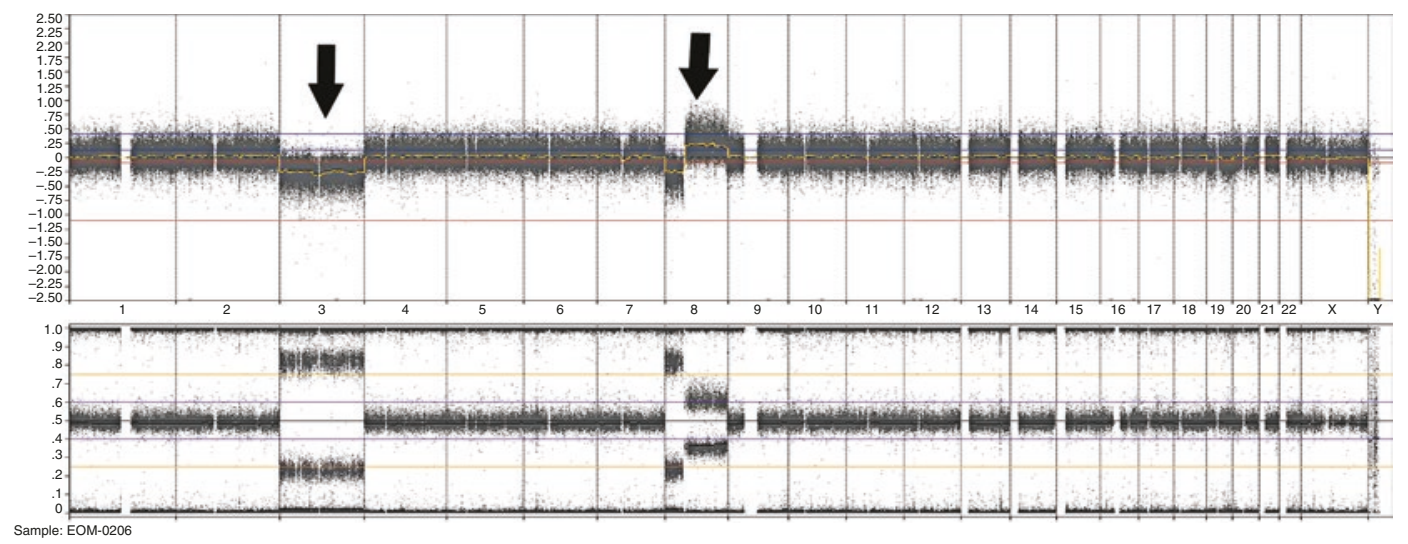

Fig. 15.6 (continued)

\section{Prognostic Application}

The states of chromosomes 1, 3, 6 and 8 allow uveal melanoma to be stratified into good and bad prognostic categories. A technique called MLPA (multi-ligation-dependent probe amplification), which is a variation of PCR, can be used to test for these chromosomal changes [18] (Fig. 15.6b).

\section{Flow Cytometry}

\section{Diagnostic Application}

This technique is used in some centres to ascertain whether a neoplastic population of $\mathrm{B}$ or $\mathrm{T}$ cells are present in vitreous or aqueous biopsies, in limited material. It is a powerful technique for the diagnosis of lymphoma [19]. Multiple 
antibodies directed to various lymphoid cell proteins, including kappa and lambda light chains, are applied as a cocktail to an unfixed suspension of lymphoid cells.

\section{Fluorescence In Situ Hybridisation (FISH)}

This technique uses fluorescent-tagged DNA or RNA probes to detect the presence or absence of a specific chromosome or the identification of two genes involved in a translocation. It can be used on cytology and paraffin-embedded tissue.

\section{Diagnostic Application}

Many sarcomas have distinctive, diagnostic recurrent genetic translocations. The example in Fig. 15.6c shows a FISH analysis of an orbital alveolar rhabdomyosarcoma with the diagnostic 1:13 translocation, which is also important as a prognostic marker in this tumour [20].

\section{Prognostic Application}

Uveal melanoma can have its chromosome 3 and 8 status tested by FISH [10, 12, 13] (Fig. 15.6d).

\section{Chromosomal Microarray Analysis (aCGH and SNP)}

Techniques such as array comparative genomic hybridisation (aCGH)[21] and single nucleotide polymorphism (SNP) chromosomal arrays [22] are powerful tools to detect genome-wide copy number changes in chromosomes. Furthermore, SNP arrays can detect copy-neutral changes and loss of heterozygosity. These techniques can be applied to fresh and paraffin-embedded tumour tissue successfully.

\section{Diagnostic Applications}

Can be used to help differentiate benign nevus from melanoma of the skin.

\section{Prognostic Application}

Can be used in uveal melanoma prognostic chromosomal analysis (Fig. 15.6e, f).

\section{Tumour Prognostic Factors}

Histopathology reports contain critical bits of information that will reflect the biological behaviour of the tumour; hence, its prognosis will trigger specific clinical management. What follows are brief descriptions of prognostic factors for some ocular tumours impacting on clinical management.

Every prognostic factor for every ocular tumour cannot be reproduced here. The relevant chapters in the TNM classification of Malignant Tumours (8th edition-UICC) [14] and the AJCC Cancer Staging Manual (8th edition) [15] have comprehensive lists of prognostic factors for all major ophthalmic tumours. Additionally, the tumour-reporting guidelines/datasets from the College of American Pathologists [23, 24] and the Royal College of Pathologists UK [25, 26] are a very comprehensive guide to macroscopic and microscopic prognostic factors for ocular tumours. Tumour prognostic factors from a pathological perspective can be macroscopic, microscopic and molecular/genetic.

\section{Examples of Tumour Prognostic Factors Encountered in Ophthalmic Histopathology Reports}

\section{Eyelid Basal Cell Carcinoma [14, 15, 27]}

The growth pattern of basal cell carcinoma will be mentioned in a report. Infiltrating and/ or sclerosing/morphoea and/or micronodular growth patterns are high-risk growth patterns. These growth patterns correlate with a significantly increased risk for local recurrence and very occasionally metastasis, hence high risk. The clearance of the tumour in 'mm' from specific margins will be mentioned in the report. Contaminated margins will trigger further treatment to ensure clearance.

\section{Conjunctival Melanoma [14, 15]}

For conjunctival melanoma, the site and depth of invasion determine the ' $\mathrm{pT}$ ' staging of these tumours. Tumours of the palpebral, forniceal and caruncular conjunctiva are higher risk compared 
to bulbar conjunctival tumours. The higher risk relates to recurrence and metastatic rates. The deeper the invasive component, the higher the pT stage.

\section{Retinoblastoma [14, 15, 23, 24]}

The presence of 'high-risk' histopathological factors on a histopathology report of a retinoblastoma enucleation includes 'massive choroidal invasion', 'extra-scleral tumour extension', 'optic nerve invasion' and 'anterior chamber extension'. These features will lead to post-enucleation chemotherapy.

\section{Uveal Melanoma [14, 15, 25, 26]}

Iris melanomas have a much better prognosis that ciliary body and choroidal located tumours. Ciliary body and choroidal uveal melanomas with monosomy 3 and iso-chromosome $8 \mathrm{q}$ gain will have a poor prognosis, compared to tumours with balanced genetics.

\section{Orbital Alveolar Rhabdomyosarcoma}

Histology reports will make the distinction between the different subtypes of orbital rhabdomyosarcoma as they have different prognoses. An alveolar growth pattern which shows a 1:13 or 2:13 translocation [28] has is more aggressive and of higher risk for recurrence and metastasis compared to the embryonal variant.

\section{References}

1. Fletcher CDM. Diagnostic histopathology of tumors. 4th ed. Philadelphia: Elsevier Saunders; 2013.

2. Maudgil A, Salvi SM, Tan JH, Mudhar HS. Improving the interaction between the ophthalmology and histopathology departments. Eye (Lond). 2011;25(8):998-1004.

3. Suvarna KS, Layton C, Bancroft JD. Bancroft's theory and practice of histological techniques. 7th ed. Oxford: Churchill Livingstone; 2013.

4. Ford AL, Mudhar HS, Farr R, Parsons MA. The ophthalmic pathology cut-up part 1: the enucleation and exenterations specimen. Curr Diagn Pathol. 2005; 11:284-90.

5. Ford AL, Mudhar HS, Farr R, Parsons MA. The ophthalmic pathology cut-up part 2: the enucleation and exenterations specimen. Curr Diagn Pathol. 2005;11:340-8.
6. Kumar V, Abbas AK. Fausto N Aster Robbins and Cotran pathological basis of disease. 8th ed. Philadelphia: Elsevier/Saunders; 2015.

7. McLean IW, Foster WD, Zimmerman LE, Gamel JW. Modifications of Callender's classification of uveal melanoma at the armed forces Institute of Pathology. Am J Ophthalmol. 1983;96:502-9.

8. Folberg R, Rummelt V, Parys-Van Ginderdeuren R, Hwang T, Woolson RF, Pe'er J, et al. The prognostic value of tumor blood vessel morphology in primary uveal melanoma. Ophthalmology. 1993;100:1389-98.

9. Prescher G, Bornfield N, Becher R. Non-random chromosomal abnormalities in primary uveal melanoma. J Natl Cancer Inst. 1990;82:1765-9.

10. Sisley K, Rennie IG, Parsons MA, Jacques R, Hammond DW, Bell SM, et al. Abnormalities of chromosomes 3 and 8 in posterior uveal melanoma correlate with prognosis. Genes Chromosomes Cancer. 1997;19:22-8.

11. Onken MD, Worley LA, Char DH, Augsburger JJ, Correa ZM, Nudleman E, et al. Collaborative ocular oncology group report number 1: prospective validation of a multi-gene prognostic assay in uveal melanoma. Ophthalmology. 2012;119:1596-603.

12. Coupland SE, Lake SL, Zeschniqk M, Damato BE. Molecular pathology of uveal melanoma. Eye (Lond). 2013;27:230-42.

13. Vaarwater J, van den Bosch T, Mensink HW, van Kempen C, Verdijk RM, Naus NC, et al. Multiplex ligation-dependent probe amplification equals fluorescence in-situ hybridization for the identification of patients at risk for metastatic disease in uveal melanoma. Melanoma Res. 2012;22:30-7.

14. Brierley J, Gospodarowicz MK, Wittekind C. TNM classification of malignant tumors. 8th ed. Oxford UK: Wiley; 2017.

15. Amin MB. AJCC Cancer staging manual. 8th ed. Cham: Springer; 2017.

16. Swerdlow SH, Campo E, Harris NL, Jaffe ES, Pileri SA, Stein H, Thiele J. World Health Organization of tumors-tumors of the haematopoietic and lymphoid tissues. 4th ed. Lyon: IARC press; 2017.

17. Shah AA, Bourne TD, Murali R. BAP1 protein loss by immunohistochemistry: a potentially useful tool for prognostic prediction in patients with uveal melanoma. Pathology. 2013;45(7):651-6.

18. Damato B, Dopierala JA, Coupland SE. Genotypic profiling of 452 choroidal melanomas with multiplex ligation-dependent probe amplification. Clin Cancer Res. 2010;16(24):6083-92.

19. Davis JL, Viciana AL, Ruiz P. Diagnosis of intraocular lymphoma by flow cytometry. Am J Ophthalmol. 1997;124:362-72.

20. Mehra S, de la Roza G, Tull J, Shrimpton A, Valente A, Zhang S. Detection of FOXO1 (FKHR) gene break-apart by fluorescence in situ hybridization in formalin-fixed, paraffin-embedded alveolar rhabdomyosarcomas and its clinicopathologic correlation. Diagn Mol Pathol. 2008;17(1):14-20. 
21. Speicher MR, Prescher G, du Manoir S, Jauch A, Horsthemke B, Bornfeld N, Becher R, Cremer T. Chromosomal gains and losses in uveal melanomas detected by comparative genomic hybridization. Cancer Res. 1994;54(14):3817-23.

22. Onken MD, Worley LA, Person E, Char DH, Bowcock AM, Harbour JW. Loss of heterozygosity of chromosome 3 detected with single nucleotide polymorphisms is superior to monosomy 3 for predicting metastasis in uveal melanoma. Clin Cancer Res. 2007;13(10):2923-7.

23. https://documents.cap.org/protocols/cp-retinoblastoma-17protocol-4000.pdf

24. https://www.google.co.uk/search?q=RCPath+retinob lastoma+dataset\&gws_rd=cr,ssl\&dcr=0\&ei=qITDW YzSOKWTgAbd1YOIAg
25. http://www.cap.org/ShowProperty?nodePath=/ UCMCon/ContributionFolders/WebContent/pdf/cpuveal-melanoma-17protocol-4000.pdf

26. https://www.rcpath.org/resourceLibrary/datasetfor-the-histopathological-reporting-of-uveal-melanoma\%2D\%2D3rd-edition-.html

27. https://www.google.co.uk/search?q=rcpath+basal+c ell+carcinoma+dataset\&gws_rd=cr,ssl \&dcr=0\&ei=lI HDWbX9FeTOgAbYspjwBw

28. Barr FG. Molecular genetics and pathogenesis of rhabdomyosarcoma. J Pediatr Hematol Oncol. 1997;19:483-91.

Open Access This chapter is licensed under the terms of the Creative Commons Attribution 4.0 International License (http://creativecommons.org/licenses/by/4.0/), which permits use, sharing, adaptation, distribution and reproduction in any medium or format, as long as you give appropriate credit to the original author(s) and the source, provide a link to the Creative Commons license and indicate if changes were made.

The images or other third party material in this chapter are included in the chapter's Creative Commons license, unless indicated otherwise in a credit line to the material. If material is not included in the chapter's Creative Commons license and your intended use is not permitted by statutory regulation or exceeds the permitted use, you will need to obtain permission directly from the copyright holder. 